\title{
World Phosphate Production: Overview and Prospects
}

\author{
L. CISSE and T. MRABET \\ World Phosphate Institute, 3, Rue Abdelkader Al Mazini, 20001 Casablanca, Morocco
}

\begin{abstract}
Phosphorus is essential to all known life forms. The element phosphorus, however, is always combined with other elements and is generally found in mineral forms, as phosphates, and most often in insoluble forms. In 2001-2002, world production of phosphate rock concentrate and unbeneficiated phosphate rock for direct processing and direct application was estimated to 125 million tones. This paper provides data and information on the origins and types of phosphate rocks, the world total phosphate rock production and reserves, and an overview of and prospects for different uses of phosphate products.
\end{abstract}

\section{INTRODUCTION}

Phosphate rock is a non-renewable natural resource, mainly found in sedimentary and igneous deposits. Its sustainable production and management is of critical importance. Most of the world phosphate production is used in agriculture.

The chemical industry, mainly the manufacture of detergents and high tech products, while using a rather small portion of the world production of phosphate rock produces phosphatebased products, which play important role and have key function in everyday life.

About 95\% of the phosphate rock mined is used to produce fertilizers, animal feeds and pesticides. This important share of phosphate used in agricultural production indicates that the development of agriculture is the driving force of phosphate rock production. Meanwhile, there is a need to further the use of phosphorus compounds in various other sectors including pharmaceutical and food industry, and household applications and in new high tech applications, such as sensors, lasers, etc.

\section{THE ROLE AND IMPORTANCE OF PHOSPHORUS}

Phosphorus crystallises into two physical forms that are "White Phosphorus" with tetrahedral structure and "Red Phosphorus", which exists under polymeric chains. Phosphorus is generally found in mineral forms, as phosphates, most often insoluble.

Phosphorus is essential to all known life forms. It is the second most abundant mineral in the human body, surpassed only by calcium. It makes about $1 \%$ of today body weight and is largely confined to the skeleton in addition to an important part of the active structure of the muscles, central nervous systems and the energy circuits.

Phosphorus compounds are important ingredients in high-grade detergents, cleaning agents, dental creams, toothpastes, flame retardants, stabilizer of plastics, corrosion inhibitors, dispersion agents in paints and primers and metal surface treatment. 
Phosphorus compounds are also excipients in the pharmaceutical industry and are widely used in the food industry, in canned food and in freezing, thawing and cooking processes.

Phosphorus is all around us: in lakes, streams, oceans, seas and in the earth. Nowadays, it is difficult to go through everyday life without coming into contact with objects in which phosphorus compounds are either an ingredient or in which a phosphorus compound is used in its processing.

\section{ORIGIN OF PHOSPHATE ROCKS}

There are two main types of phosphate rock deposits:

(1) Sedimentary phosphate deposits that provide more than $80 \%$ of the total world production of phosphate rock, and:

(2) Igneous phosphate deposits, mainly mined in Russia, the republic of South Africa, Finland and Brazil. Igneous ores are often low in grade but through beneficiation processes can provide phosphate rock with $30 \% \mathrm{P}_{2} \mathrm{O}_{5}$.

Phosphate deposits are widespread throughout the world, occurring almost on all continents. In Figure 1 are presented those deposits that are currently mined, have been mined in the past or are potentially economically viable.

Igneous phosphate deposits are often associated with carbonates and/or alkalic intrusions. Sedimentary phosphate deposits occur throughout the geological time scale and most of them were formed in offshore marine conditions on continental shelves. Sedimentary phosphate rocks have a wide range of chemical compositions and great variations in physical forms. Island deposits are a type of sedimentary deposits associated with oceanic islands; they have been an important source of phosphate rock for more than 100 years but intensive exploitation resulted in the depletion of most of these deposits.

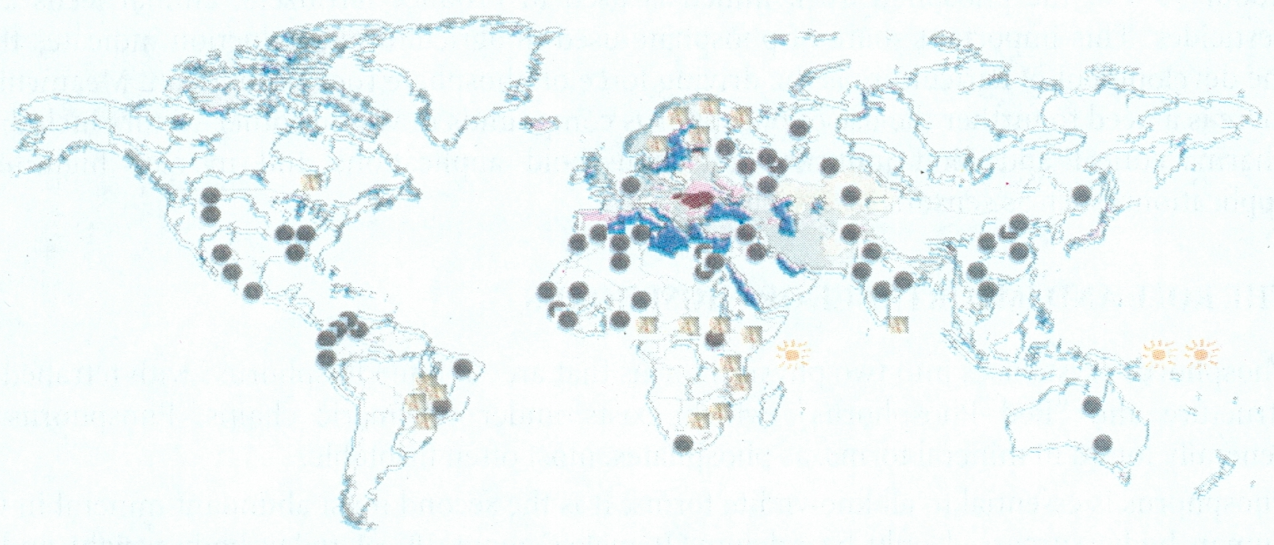

ECONOMIC AND POTENTIALLY ECONOMIC PHOSPHATE DEPOSITS OF THE WORLD

\section{Sedimentary Deposits}

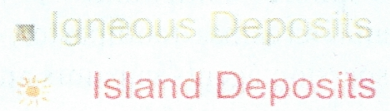




\section{PHOSPHATE ROCK PRODUCTION AND RESERVES}

Commercial production of phosphate rock began in the mid- $19^{\text {th }}$. In 1847,500 tonnes were mined in Suffok (United Kingdom). The world production increases to over 10 million tons in 1928, and over 100 million tones in 1974. In 2001-2002, world production of phosphate rock was around 125 million tonnes ${ }^{2}$.

About $93 \%$ of the phosphate rock produced are used to produce mineral fertilizers, essentially, DAP (Diammonium Phosphate), MAP (Monoammonium phosphate), TSP (Triple Superphosphate), SSP (Single Superphosphate) and phosphoric acid, and animal feed.

The six IMPHOS' Member companies, which are CPG (Tunisia), OCP (Morocco), JPMC (Jordan), ICS (Senegal), FERPHOS (Algeria) and IFG (Togo) currently produce more than $30 \%$ of world phosphate rock production, export nearly $50 \%$ of World phosphate rock exports, and represent almost $70 \%$ of recoverable phosphate reserves ${ }^{3}$. Four countries that are USA, China, Morocco and Russia collectively produce 70 to $75 \%$ of the world's total phosphate rock. In 2001, the top countries that produced 95\% of the world's total phosphate rock are USA, Morocco, China, Russia, Tunisia, Jordan, Brazil, Israel, the Republic of South Africa, Syria, Senegal, Australia, India, Togo, Egypt and Algeria (Figure 2). Global reserves and potential reserves ${ }^{4}$ are presented in table 1.

\section{World Phosphate Rock Production in 2001}

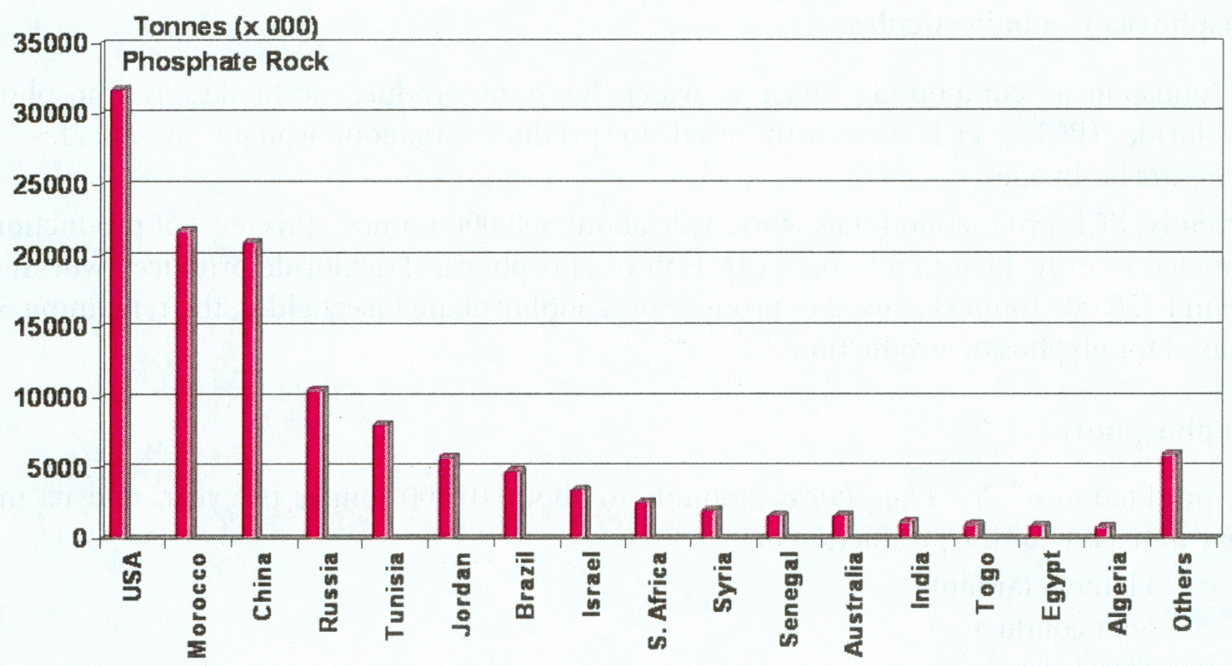


Table 1: Global Phosphate Reserves and Potential Reserves

\begin{tabular}{|l|c|c|}
\hline \multicolumn{1}{|c|}{ Country } & Reserves $^{(1)}(\%)$ & Potential Reserves $^{(1)}(\%)$ \\
\hline United States & $4-10$ & $7-13$ \\
China & $2-25$ & $2-10$ \\
Russia & 3 & $7-10$ \\
Morocco & $46-53$ & 63 \\
Jordan & $2-3$ & $1-3$ \\
Tunisia & 1 & 1 \\
South Africa & $9-22$ & $3-22$ \\
Brazil & $1-3$ & $1-2$ \\
Iraq & 1 & 3 \\
Peru & 1 & - \\
\hline \multicolumn{1}{|c|}{ Total $\mathrm{P}_{2} \mathrm{O}_{5}$} & $3.6-8.0$ (billion tons) & $11-22$ (billion tons) \\
\hline
\end{tabular}

(1) In \% of the total expressed in billion tons of $\mathrm{P}_{2} \mathrm{O}_{5}$

Of the four major producers, Moroccan reserves account for around 50\% of the world total. With phosphate consumption growth estimated at $1-2 \%$ per year, global phosphate reserves extend, for all intents and purposes well into the future, for centuries. Meanwhile, depletion of the most economically exploitable reserves can be estimated to occur within a period of 100-130 years.

\section{NON-FERTILIZER PHOSPHATE PRODUCTS}

About $95 \%$ of the world's total phosphate rock production are used in agriculture through fertilizers, pesticides and animal feeds. About $5 \%$ are therefore used in non-agricultural products and/or applications. As phosphorus in animal feeds is the topic of a separate paper, this paper will develop the use of phosphorus in pesticides and in non-agricultural applications.

\section{Phosphorus Use in Pesticides}

The phosphorus compound, which is widely used to produce pesticides, is Phosphorus Trichloride $\left(\mathrm{PCI}_{3}\right) . \mathrm{PCI}_{3}$ is mostly used to produce organophosphate insecticides and glyphosate herbicides.

Currently, $\mathrm{PCI}_{3}$ production totals worldwide about 500,000 tonnes ${ }^{5}$; this level of production is estimated to grow by 4 to $5 \%$ per year. Half of phosphorus Trichloride produced worldwide (around 250,000 tonnes) is used to produce organophosphate insecticides; the remaining 50\% are used for glyphosate production.

\section{Red phosphorus}

The production of Red Phosphorus amounts to about 10,000 tonnes per year ${ }^{5}$ and its main applications are for the production of:

- Flame retardants

- Semiconductors

- Fireworks

- Matches

Annual growth of the production of red phosphorus is estimated for the near years to come to be around 1 to $2 \%$. 


\section{Phosphates in foodstuff}

The commercial use of food-grade phosphates amounts currently to hundreds of thousands tones. The most widely used phosphorus products in foodstuff are:

- Phosphoric acid in soft drinks

- Sodium phosphates in treating fish filets and freshly killed poultry

- Sodium pyrophosphates in baking mixtures as acidulants, and in potato processing

\section{Phosphates in household applications}

Phosphorus compounds play important role in several household applications. They are used as raw materials in:

- High grade detergents

- Cleaning agents

- Dental cream or tooth-paste

- Flame retardants for clothing (special for children's sleep wears) and carpets, rugs and curtains

- Motor vehicle materials

\section{CONCLUSION}

World phosphate reserves are sufficient to supply the world with the required amounts and types of needed phosphate products for some centuries to come. Meanwhile, it is worth mentioning that high grade and economic reserves are being depleted, which could result in mining slightly more costly resources and/or lower grade phosphate rocks.

The 95\% of the global phosphate production used in agricultural production much contributed to providing enough food to ever growing world population. The large amount and high quality of food obtained today worldwide, and in particular in developing countries, are largely due to the use of phosphate fertilizers, phosphorus-based herbicides and insecticides, and plant hormone, let alone the use of phosphorus in animal feeds.

There are many non-agricultural applications of phosphate-based products. These applications are currently using limited quantities of phosphates, but they cover various sectors essential to today life.

Newer technologies, some based on incremental improvement of existing technologies and others on entirely new concepts, should be developed to further the use of phosphates in the non-agricultural sector.

\section{REFERENCES}

1- Fertilizer Manual, Edited by the United Nations Industrial Development Organization (UNIDO) and the International Fertilizer Development Center (IFDC), in Kluwer Academic Publishers (The Netherlands, 1998).

2- International Fertilizer Industry Association (IFA), Phosphate rock statistics (2002).

3- The World Phosphate Institute, Strategic Plan of Action 2001-2010 (2000).

4- IMPHOS Phosphate Newsletter, Phosphorus Availability in the $21^{\text {st }}$ century (issue $\mathrm{n}^{\circ}$ 14/2001).

5- The World Phosphate Institute (IMPHOS, Unpublished data (2002). 